\section{Reflecting on the First Three Years of TOPEX/POSEIDON}

\section{Lee-Lueng Fu, Chester J. Koblinsky, Jean-Francois Minster, and Joel Picaut}

The U.S./France TOPEX/POSEIDON (T/P) satellite, in orbit since August 1992, is the first global ocean observing system specifically designed to study ocean dynamics. The satellite uses a state-of-the-art radar altimeter system to determine the sea level-the height of sea surface relative to a reference ellipsoid-with an unprecedented accuracy. It is supplying a wealth of new information on ocean circulation and the patterns of the global seasonal cycle, low-frequency wave dynamics, gyre-scale variabilities, ocean tides, and global mean sea level variations. These observations are being used to test ocean circulation theories and the ever-maturing computer models of ocean general circulation.

T/P observations cover the global oceans from $66^{\circ} \mathrm{S}$ to $66^{\circ} \mathrm{N}$ every 10 days, allowing oceanographers to routinely monitor the dynamic global ocean. For the first time, the ocean is being accurately sampled with sufficient spatial and temporal resolution to address its variability at frequencies and wavenumbers (spatial frequency) previously unattainable by in situ observations. The mission was also designed to measure ocean tides, resulting in the most accurate deep ocean tide models to date. The tidal signals were then removed from the sea level measurements to make the data suitable for ocean circulation studies. The radar altimeter also measures wind speed and wave height, which are part of the mission's data product in addition to sea level. Many results from the mission have been published in two special issues of the Journal of Geophysical Research (Vol.99 No. C12, 1994; Vol. 100, No. C12, 1995).

\section{Large-Scale Variabilities}

The frequency-wavenumber spectrum of global ocean variability is crucial for understanding ocean dynamics. An estimate of such a spectrum, the first based on real data, was

Lee-Lueng Fu, MS 300-323, Jet Propulsion Laboratory, Catifornia Institute of Technology, Pasadena, CA 91109; Chester J. Koblinsky, Ocean and Ice Branch, NASA Goddard Space Flight Center, Greenbelt, MD 20771; Jean-Francois Minster, Laboratoire VNES/CNRS, Groupe de Recherche en Geodesie Spatiale, Toulouse, Developpement en Cooperation (ORSTOM)

Noumea, New Caledonia France; Joel Picaut, Groupe SURTROPAC, l'Institut Francais de Recherche Scientifique, pour le made by Wunsch and Stammer [1995]. A major characteristic of the spectrum is a ridge of variance at the annual period for wavelengths ranging from 500 to $10,000 \mathrm{~km}$. Appreciable energy levels are revealed at shorter periods as well. The spatial pattern of the annual cycle was studied by many investigators. A hemispheric asymmetry in the amplitude is observed [e.g., Cheney et al., 1994]; mean sea level annual variation in the Northern Hemisphere is larger than that in the Southern Hemisphere by a factor of 2 . This asymmetry is consistent with the greater seasonal changes of oceanic heat content in the Northern Hemisphere, but it was not detected by other satellite altimeters due to large orbit errors. This new observation gives us a better understanding of the global air-sea heat exchange.

The large-scale variability at intraseasonal timescales, periods shorter than 180 days, is difficult to study using in situ data due to inadequate spatial sampling in the presence of the ubiquitous mesoscale eddies. T/P observation revealed for the first time the geographic distribution of the intraseasonal large-scale variability and its barotropic (depth independent) nature as a forced response to wind [Chao and
$F u, 1995]$. At lower frequencies, the large-scale variability exhibits predominantly westward phase propagation, a characteristic of Rossby waves. At high latitudes, the phase speeds of these waves are found to be $2-3$ times faster than theoretical predictions based on standard theory [Chelton and Schlax, 1996]. This indicates that the response of high-latitude ocean to tropical events such as El Niño is much faster than previously thought. In the Antarctic Circumpolar Current, evidence of eastward propagation due to the effect of mean flow on Rossby waves was reported for the first time [Hughes, 1995].

$\mathrm{T} / \mathrm{P}$ is leading to many new findings about the energetics of ocean currents. Qiu [1995] reported a linear increase in eddy energy south of the Kuroshio Extension as a result of conversion of mean flow kinetic energy via instability. White and Heywood [1995] demonstrated that the eddy kinetic energy in the North Atlantic Current region is related to the migration of the current with interannual variations of the wind stress curl field. The unprecedented accuracy of T/P data has led D. Stammer of MIT to discover a universal wavenumber spectrum for the mesoscale variability, specified by latitude, energy level, and vertical stratification of water.

The T/P observation has also provided the first test bed for high-resolution computer simulations [e.g., Semtner, 1995]. The overall geographic patterns of sea level variability, the seasonal cycle, as well as real-time large-scale sea level variations are in reasonable agreement; their discrepancies suggest that physical processes may be missing from the model. The sea level variance produced by the model is

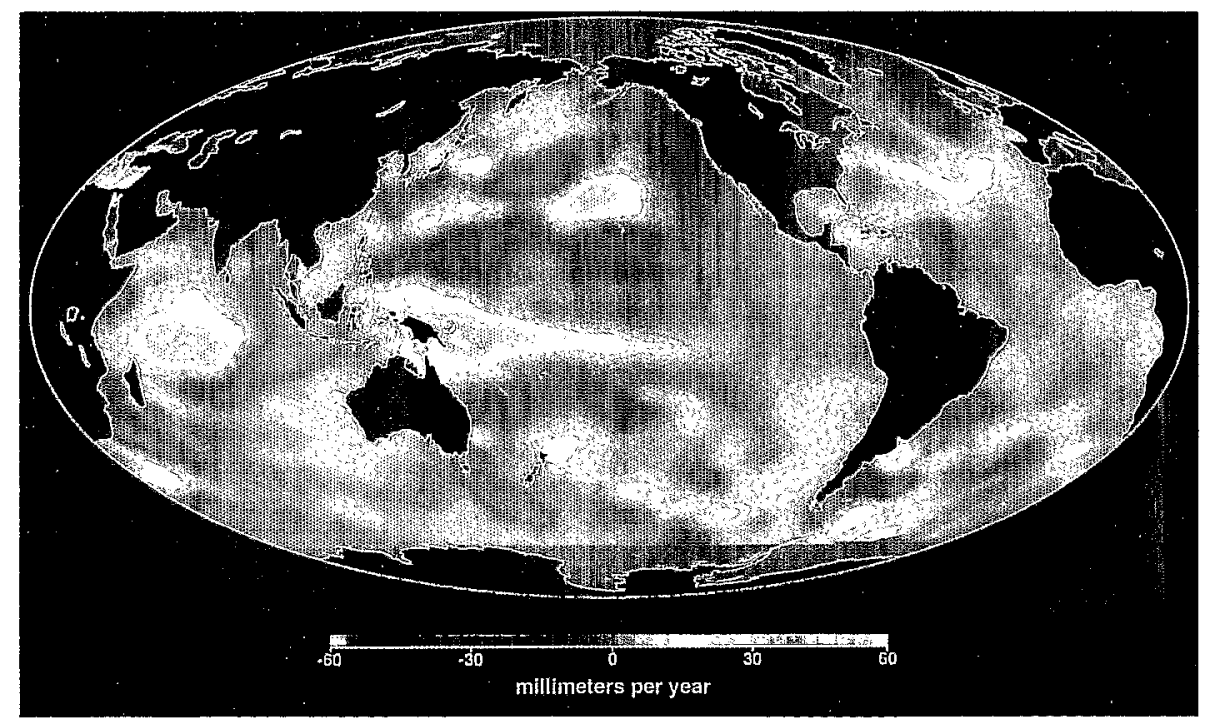

Fig. 1. The linear trends of sea level change estimated from the TOPEX/POSEIDON observation during a 3-year period from September 1992 to August 1995. The global average indicates a sea level rise at a rate of $4-6 \mathrm{~mm} /$ year. However, the spatial patterns are dominated by the regional interannual variabilities of the ocean. For example, the rise in the westem Pacific is related to the prolonged series of El Niño events during 1991-1995. 
generally less than the observation by a factor of 2 or more. The discrepancy is most pronounced in eddy-rich regions, but its causes and consequences remain obscure. The model might need even higher spatial resolution to fully resolve the mesoscale eddies. Assimilation of the T/P data into models has shown improvements in the simulation of the mean flow and the eddy kinetic energy distribution, as well as the subsurface current field [e.g., Blayo et al., 1994].

\section{Tropical Dynamics}

T/P has covered more than half of the prolonged series of El Niño events during 19911995, which mostly involved the Tropical Pacific Ocean and to some extent, the Indian Ocean. As for the Tropical Atlantic Ocean, anomalous high sea level associated with a warm event was observed in 1995. A combination of T/P and in situ observations has allowed comprehensive studies of these events. With the vanishing of the Coriolis force toward the equator, very accurate sea level is needed in the equatorial regions to derive correct surface geostrophic currents. Given the numerous corrections involved in measuring sea level from space, in situ validation is a fundamental step prior to any use of altimetry data. The T/P altimeter data has detected large-scale sea level to within $2-3 \mathrm{~cm}$, as anticipated. Comprehensive tests to estimate geostrophic currents from T/P data have also been conducted. Many successful comparisons were made to direct current observations from the Tropical Ocean Global Atmosphere-Tropical Atmosphere Ocean (TOGA-TAO) moorings and drifting buoys.

Analysis of the space-time structure of the T/P sea level estimates together with the TOGATAO observations indicates that sea level variability in the Pacific equatorial band resulted from equatorial Kelvin and Rossby wave activities associated with the El Niño events in the past three years [e.g., Busalacchi et al., 1994]. These waves and their reflection at the oceanic boundaries are believed to be important mechanisms for the formation and decay of $\mathrm{El}$ Niño. Observations of such mechanisms are difficult using in situ methods. Boulanger and Menkes [1995] did not find any evidence of Rossby wave reflection at the western boundary to terminate the 1992-1993 warm event as theory suggests. However, a recent study by J.P. Boulanger and L. - L. Fu suggests that firstmode downwelling Rossby waves reflected into downwelling Kelvin waves from January to July 1994. This wave reflection mechanism may have played a role in the onset of the 1994-1995 boreal winter warm event.

The throughflow from the Pacific to the Indian Ocean may be important in determining the El Niño Southern Oscillation cycle. R. Lukas of the University of Hawaii and collaborators have developed indices of the throughflow using $T / P$ sea-surface height differences between the western equatorial Pacific and the eastern Indian Ocean. The comparison with the Davao-Darwin sea level index indicates that $\mathrm{T} / \mathrm{P}$ data are better for determining the seasonal cycle of the throughflow as well as its weakening during El Niño.

Using T/P data, S. Arnault of ORSTOM-Paris and Y. Menard of Centre National d'Etudes Spatiales (CNES) detected a strong warm event in the Tropical Atlantic that began in early 1995. The sea surface height anomalies in the Gulf of Guinea began to rise as early as January 1995 , reaching more than $5 \mathrm{~cm}$ compared to the 1993-1994 mean sea-surface height anomalies. This description from altimetry data is in excellent agreement with sea-surface temperature and wind data analysis.

\section{Ocean General Circulation}

A basic motive of satellite altimetry is to provide ocean dynamic topography - the deviation of sea level from the Earth's equigeopotential surface (defined as the geoid)-and, therefore, a reference surface geostrophic velocity for determining general circulation at all depths. Initial estimates of this surface using T/P data at a horizontal resolution of about $1000 \mathrm{~km}$ [Nerem et al., 1994] are estimated to have a total error greater than $10 \mathrm{~cm}$ rms within $30^{\circ}$ of the equator, but smaller errors $(<10 \mathrm{~cm} \mathrm{rms})$ poleward of $30^{\circ}$ latitude. Inaccuracies in the geoid are the dominant source of error in these computations. Even with these apparently large errors, $T / P$ has provided new information about general circulation in the ocean. Since the launch of $T / P$ there has been a major effort to improve the Earth geoid model. A variety of new stateof-the-art models have been completed over the past few years, and their global cumulative standard errors are now about $5 \mathrm{~cm}$ rms for a resolution of $1400 \mathrm{~km}$. At higher resolution the geoid errors become larger than the magnitude of the dynamic topography, rendering the altimetric estimates unreliable. At the resolution of $1400 \mathrm{~km}$, errors in upper ocean geostrophic currents outside of $\pm 10^{\circ}$ latitude are $\sim 2$ $\mathrm{cm} / \mathrm{s} \mathrm{rms}$.

Over the past 3 decades numerical general circulation models of the ocean have improved dramatically with the increase in computational power [Semtner, 1995]. These models can now provide realistic simulations of most of the basic features of the general circulation. The T/P data, because of their global coverage and accuracy, have revealed strengths and weaknesses of the models. The rms difference in dynamic topography between a 2-year mean from the Los Alamos Parallel Ocean Program model and a 2-year mean from T/P at scales larger than $1000 \mathrm{~km}$ is $14 \mathrm{~cm}$. Given the $10-\mathrm{cm}$ error estimate for the geoid, this implies that the model error is about $10 \mathrm{~cm}$ as well at these scales. However, the geoid errors are smaller at larger scales; they become less than the errors of model simulations and hydrographic estimates at scales larger than about $2500 \mathrm{~km}$ (R. Rapp, personal communication, 1996). The T/P results have thus provided new information on the ocean circulation at the scales of the ocean basins.

A collaboration between the U.S. Defense Mapping Agency and NASA's Goddard Space Flight Center is underway to improve the Earth's gravity model through a reprocessing of the unclassified database, in addition to some recently released classified gravity data. This effort may improve the geoid accuracy in ocean regions at scales greater than $1400 \mathrm{~km}$ and refine the dynamic topography of the ocean gyres from T/P data. However, at this resolution, the more dramatic features of the geoid over trenches, sea mounts, and ridges, as well as the strong ocean currents near western boundaries and the circumpolar current, are not resolved. Only an independent satellite mission to measure the gravitational field will provide the necessary increase in geoid accuracy and resolution to significantly enhance the use of T/P data for general circulation research.

\section{Mean Sea Level Variation}

The remarkable accuracy and precision of $T / P$ data indicates that the evolution of the mean sea level and its geographical distribution may be observed by this system, but this goal remains extremely challenging in terms of accuracy, especially due to the systematic errors in the various components of the measurement system. Estimates based on 3 years of $T / P$ data indicate a global mean sea level rise at a rate of 4-6 mm/year [e.g., Nerem, 1995]. A number of independent calibration experiments indicate that an additional drift at a rate of about 2 $\mathrm{mm} /$ year is present in the sea level measurement, resulting in a revised sea level rise of 2-4 $\mathrm{mm} /$ year. However, the cause for this additional drift is not understood yet.

The lower bound of the estimated value, 2 $\mathrm{mm} /$ year, is fairly close to the rate of sea level rise estimated from tide gauge data taken since the beginning of the century, but these data also suggest large variations of sea level rise with time. However, the apparent sea level rise is not spread homogeneously over the ocean. The map in Figure 1 (based on data provided by $S$. Nerem [1995]) shows the rate of a linear sea level change estimated from a least squares fit of a linear term plus the annual and semiannual harmonics to the first 3 years' worth of T/P data (cycles 1-108). Because of the short duration of the record, the linear trends are dominated by the interannual variability of the ocean. For instance, the large sea level rise in the western Pacific was related to the prolonged series of El Niño events during 1991-1995. The similar sea level rise in the westerm Indian Ocean was probably also related to the El Niño events. The sea level rise north of Hawaii is thought to be related to the passing of a low-frequency Rossby wave. 
These sea level changes at interannual timescales make it impossible to use the current data set to detect long-term sea level rise caused by possible global warming, and it underscores the need for acquiring a multidecadal, multimission time series of altimeter data of T/P quality.

The patterns of sea level change shown in Figure 1 are the leading mode of variability after the annual and semiannual signals are removed from the data. This mode of sea level change is coherent in space and time with the sea surface temperature (SST) signal, which was rising at a globally averaged rate of $0.07^{\circ} \mathrm{C}$ year during 1993-1994 [Nerem, 1995]. This suggests that the sea level signal is probably related to the warming of the ocean. Taking the higher rate of sea level rise of 4-6 $\mathrm{mm} /$ year, the sea level to SST drift ratio is $6-9$ $\mathrm{cm} /{ }^{\circ} \mathrm{C}$. Given typical values of the seawater thermal expansion coefficient and assuming that the SST drift signal is correlated with the temperature evolution below the surface, this ratio typically requires a temperature change over a layer 300-450 $\mathrm{m}$ thick. This seems large, since the timescale of these observed variations is short compared to the timescale needed for heat invasion in such a layer. Of course, SST may be a poor indicator of subsurface signals, especially in the tropics. However, taking the lower bound of the estimated sea level rise at $2 \mathrm{~mm} /$ year, only a layer of 150 $\mathrm{m}$ would need to be heated, which is more realistic. The correlation between sea level and SST signals is encouraging and indicates that actual oceanographic interannual variations are being observed.

T/P data suggest that the seasonal variation of the mean sea level is very small. Yet, mean SST shows a seasonal signal of $0.5^{\circ} \mathrm{C}$ in amplitude, which should induce a seasonal steric height signal of the order of $5 \mathrm{~mm}$ amplitude (assuming an average mixed layer depth of 50 m). However, seasonal water mass transfer to the atmosphere ( $3 \mathrm{~mm}$ equivalent sea level amplitude) and to the continents could cancel this steric height effect. In fact, T/P data might provide useful information on the latter, which is poorly known.

\section{Future Work}

NASA plans to operate the T/P satellite through at least 1998, providing up to 6 years' worth of data. Among many fruitful applications of this growing data set, an enterprise should develop in which the data are used with computer models for routine global ocean analysis and predictions. To make a real impact on understanding the global ocean change and its role in climate, global observing systems of the quality of $\mathrm{T} / \mathrm{P}$ need to be maintained in the future. The dynamic boundary condition for ocean circulation provided by altimetry is crucial for a global climate observing system. A follow-on mission to T/P is currently being developed by France and the United States with its launch planned for 1999

\section{Acknowledgments}

This article was based on results presented at the TOPEX/POSEIDON Science Working Team Meeting and the Symposium on Operational Oceanography and Satellite Observation, October 16-20, 1995, in Biarritz, France. We thank Yves Menard for organizing the meetings and Steve Nerem for providing the data used in Figure 1. We also thank Richard Rapp, Detlef Stammer, Steve Nerem, Bruce Douglas, Tony Busalacchi, Eli Katz, Claire Perigaud, Ted Strub, and Jean-Philippe Boulanger for their helpful comments. Research was carried out in part (LLF) by the Jet Propulsion Laboratory, California Institute of Technology, under a contract with the National Aeronautics and Space Administration. Support from the TOPEX/POSEIDON Project, France's Centre National d'Etudes Spatiales, as well as the U.S. National Oceanic and Atmospheric Administration is also acknowledged.

\section{References}

Blayo, E., J. Verron, and J. M. Molines, Assimilation of TOPEX/POSEIDON altimeter data into a circulation model of the North Atlantic, J. Geophys. Res., 99, 24,691, 1994.

Busalacchi, A. J., M. J. McPhaden, and J. Picaut, Variability in the equatorial Pacific sea surface topography during the Verification Phase of the TOPEX/POSEIDON mission, $J$. Geophys. Res., 99, 24,725, 1994.

Boulanger, J. -P., and C. Menkes, Propagation and reflection of long equatorial waves in the Pacific ocean during the 1992-1993 El Niño, J. Geophys. Res., 100, 25,041, 1995.

Chao, Y., and L. - L. Fu, A comparison between the TOPEX/POSEIDON data and a global ocean general circulation model during 1992-93, J. Geophys. Res., 100, 24,965, 1995.

Chelton, D. B., and M. G. Schlax, Global observations of Oceanic Rossby waves, Science, in press, 1996

Cheney, R., L. Miller, R. Agreen, N. Doyle, and J. Lillibridge, TOPEX/POSEIDON: The $2-\mathrm{cm}$ solution, J. Geophys. Res., 99, 24,555, 1994.

Hughes, C. W., Rossby waves in the Southern Ocean: A comparison of TOPEX/POSEIDON altimetry with model predictions, J. Geophys. Res., 100, 15,933, 1995.

Nerem, R. S., Measuring global mean sea level variations using TOPEX/Poseidon altimeter data, J. Geophys. Res., 100, 25,135, 1995.

Nerem, R. S., E. J. Schrama, C. J. Koblinsky, and B. D. Beckley, A preliminary evaluation of ocean topography from the TOPEX/POSEIDON mission, J. Geophys. Res., 99, 24,565, 1994.

Qiu, B., Variability and energetics of the Kuroshio Extension and its recirculation gyre from the first two-year TOPEX data, $J$. Phys. Oceanogr., 25, 1827, 1995.

Semtner, A. J., Modeling ocean circulation, Science, 269, 1379, 1995.

White, M. A., and K. J. Heywood, Seasonal and interannual changes in the North Atlantic subpolar gyre from Geosat and TOPEX/POSEIDON altimetry, $J$. Geophys. Res., 100, 24,931, 1995.

Wunsch, C., and D. Stammer, The global frequency-wavenumber spectrum of oceanic variability estimated from TOPEX/POSEIDON altimeter measurement, J. Geophys. Res., $100,24,895,1995$. 


\title{
Reflecting on the First Three Years of TOPEX/POSEIDON
}

\author{
Lee-Lueng Fu, Chester J. Koblinsky, \\ Jean-Francois Minster, and \\ Joel Picaut
}

Reprinted from Eos, Transactions American Geophysical Union

Fonds Documentarre ORSTON3 